\title{
AVALIAÇÃO, ACREDITAÇÃO E INTERNACIONALIZAÇÃO DA EDUCAÇÃO SUPERIOR: INTERFACE E TENDÊNCIAS
}

\author{
Gabriella de Camargo Hizume (Unioeste)* \\ https://orcid.org/0000-0001-8321-356X
}

\section{RESUMO}

A garantia de qualidade da educação superior tem se tornado uma das principais políticas públicas tanto na esfera nacional quanto internacional. Muitas vezes associada ao desenvolvimento econômico e à empregabilidade, a formação de nível superior é cercada de expectativas dos mais diversos setores da sociedade que esperam que atenda a certos requisitos entendidos como indicadores de sua qualidade. Assim, este artigo objetiva discutir alguns dos principais elementos referentes à avaliação e à acreditação e o papel que exercem em contextos de promoção da qualidade e da internacionalização da educação superior. Para tanto, a partir de pesquisa bibliográfica, são abordados temas como qualidade e pertinência, acreditação e certificação de qualidade para, por fim, serem apresentados alguns modelos de acreditação em âmbito internacional. Concluise que a ascensão da acreditação está relacionada à flexibilização de fronteiras e às demandas de mobilidade da academia e do mercado de trabalho.

Palavras-chave: Avaliação. Acreditação. Internacionalização da educação superior.

\section{ABSTRACT}

\section{EVALUATION, ACCREDITATION AND INTERNATIONALIZATION OF HIGHER EDUCATION: INTERFACE AND TRENDS}

Quality assurance in higher education has become one of the main public policies at national and international levels. Often associated with economic development and employability, higher education is surrounded by the expectations of the most diverse sectors of society that expect it to meet certain requirements understood as indicators of its quality. Thus, this article aims to discuss some of the main elements related to evaluation and accreditation and the role they play in contexts of quality promotion and internationalization of higher education. Therefore, based on bibliographic research, topics such as quality and pertinence, accreditation and quality certification are addressed in order to, finally, present some accreditation models at the international level. It is concluded that the rise of accreditation is related to the flexibilization of borders and the demands of mobility of the academy and labor market.

Keywords: Evaluation. Accreditation. Internationalization of higher education.

\footnotetext{
* Doutoranda em Educação pela Universidade de São Paulo (USP). Professora Assistente do curso de Direito da Universidade Estadual do Oeste do Paraná (Unioeste), campus Francisco Beltrão. E-mail: gabriellahizume@usp.br
} 


\section{RESUMEN \\ EVALUACIÓN, ACREDITACIÓN E INTERNACIONALIZACIÓN DE LA EDUCACIÓN SUPERIOR: INTERFAZ Y TENDENCIAS}

La garantía de calidad en la educación superior se ha convertido en una de las principales políticas públicas nacionales y internacionales. Asociada al desarrollo económico y a la empleabilidad, la educación superior está rodeada de las expectativas de los sectores más diversos de la sociedad que esperan que cumpla ciertos requisitos entendidos como indicadores de su calidad. Así, este artículo analiza algunos de los principales elementos relacionados con la evaluación y la acreditación y el papel que desempeñan en contextos de promoción de la calidad y la internacionalización de la educación superior. A partir de la investigación bibliográfica, se abordan temas como la calidad y pertinencia, la acreditación y la certificación de la calidad para, por fin, presentar algunos modelos internacionales de acreditación. Se concluye que el ascenso de la acreditación se relaciona con la flexibilización de las fronteras y las demandas de movilidad de la academia y del mercado laboral.

Palabras clave: Evaluación. Acreditación. Internacionalización de la educación superior.

\section{Introdução}

Notadamente entre os anos de 1980 e 1990, a avaliação e a acreditação da educação superior têm se constituído como mecanismos básicos de garantia da qualidade de cursos, programas e Instituições de Ensino Superior (IES) tanto em esferas nacionais quanto internacionais. Muitas vezes ligado a linhas de fomento, o reconhecimento de qualidade propicia o financiamento de pesquisas, a concessão de bolsas de estudos em diversos níveis, a celebração de convênios de cooperação, a participação em programas de mobilidade de acadêmicos e estudantes e, até mesmo, prestígio de per si, o que favorece a consecução de patamares internacionais.

A busca em se garantir uma formação acadêmica de qualidade, amplamente reconhecida, vincula-se tanto ao entendimento de que sua natureza se refere a uma prestação de serviço que visa oferecer melhores condições para a ocupação de um posto no mercado de trabalho transnacional, como ao de que se trata de um direito que deve ser exercido em sua magnitude. Nesta esteira, observam Caillón e Robledo (2009) que o reconhecimento extraterritorial de competências figura, igualmente, entre as demandas de mobilidade da comunidade científico-acadêmica e as de investimentos empresariais do setor privado. Como coloca Siufi (2009), de um lado sopesa a exigência de mercado para o estabelecimento de níveis de qualidade do ensino superior internacionalizado e, de outro, a percepção de que os sistemas avaliativos garantem a qualidade do ensino como bem público de responsabilidade social, fulcrando-se sua extensão transfronteiriça na busca pela cooperação fraternal em defesa do desenvolvimento da humanidade.

Muito embora o tema apresente enfoques tão díspares, neste artigo serão abordadas questões que permeiam a garantia de qualidade da educação superior e que possibilitam o estabelecimento de parâmetros de comparabilidade em processos de avaliação e acreditação de sistemas educacionais distintos, sendo ao final apresentados alguns modelos de cunho transnacional. 


\section{Avaliação, Qualidade e Pertinência}

Para Verhine e Freitas (2012), a compreensão das transformações da educação superior hodiernamente só é possível se se levar em conta a avaliação como instrumento para a reorganização dos sistemas educacionais nacionais como resposta às metas sociais e econômicas de cada país em tempos de flexibilização de fronteiras. Assim, deve-se atentar para o fato de que o objetivo da avaliação está diretamente relacionado com questões de valor e requer juízos de valor ou mérito, influindo diretamente na definição do que seja qualidade em determinado momento histórico, como aponta Scriven (1967 apud FITZPATRICK; SANDERS; WORTHEN, 2004). Ainda segundo esse autor, os processos avaliativos não poderiam ser considerados neutros em face dos resultados que dele se esperam, considerando-se que toda a metodologia e a escolha de instrumentos estão voltadas para objetivos a serem alcançados pelo objeto avaliado, que pode ser tanto uma instituição, um programa, como um curso. ${ }^{1}$ Neste sentido, ponderam Rothen e Barreyro (2009) que os juízos de valor produzidos para a definição de qualidade em determinado sistema não são aleatórios, requerem minimamente elementos para o estabelecimento de uma comparação entre os objetos avaliados.

Independentemente da concepção que se adote de avaliação, para Dias Sobrinho (2003), toda avaliação compreende as dimensões política e ética além da técnica, tendo em vista que se produz, impreterivelmente, em espaços sociais de valores e de disputas de poder. Para esse autor, nesse cenário, a qualidade e a garantia da qualidade ascenderam à posição estratégica nos processos de reconfiguração da educação superior e para as políticas públicas setoriais (DIAS SOBRINHO, 2011), atentando

1 A concepção de avaliação de Scriven parte do pressuposto de que a avaliação se constrói a partir de uma carga valorativa $a$ priori sobre o objeto a ser avaliado e não a partir dele, segundo Ristoff (2003).
Torres (2009) que a qualidade da educação deve ser definida a partir do que se entende por educação e não o contrário; assim, primeiramente, devem ser definidos os parâmetros do que se entende por educação e depois o que é qualidade; daí a importância em se conceber a educação superior como direito, bem ou serviço (público ou privado).

Na discussão sobre a definição de qualidade, é trazida à baila sua dimensão social e ético-política, refletida em sua pertinência e relevância para a sociedade. Por esse prisma, o conteúdo da qualidade não seria acabado e estático, mas variável, amoldando-se aos contextos e anseios produzidos nas sociedades e nos grupos de interesse (DIAS SOBRINHO, 2011). Assim, a pertinência estaria intrinsecamente ligada à roupagem que a educação superior assume em determinada sociedade e às expectativas a seu respeito, à sua função social e a um ideal referente aos objetivos e necessidades do meio em que está inserta, de acordo com Tunnermann (2009). Dias Sobrinho (2011) chama atenção para o fato de que aos Estados também cabe zelar para que as expectativas de grupos sociais em relação à educação superior não sejam malogradas, visto que a noção de qualidade engloba suas funções econômicas e expectativas quanto à empregabilidade e melhoria da qualidade de vida.

No contexto de internacionalização da educação superior, as implicações da definição de pertinência e qualidade são projetadas para além do território nacional e envolvem não apenas as pretensões de uma determinada sociedade, mas de toda uma conjectura articulada entre atores e a opinião pública na seara internacional.

Alguns organismos internacionais têm abordado a questão da qualidade do ensino superior apontando seus elementos, como a Organização das Nações Unidas para a Educação, a Ciência e a Cultura (Unesco) e a Organização para a Cooperação e Desenvolvimento Econômico (OCDE), considerado este principal think tank. Segundo a Unesco, para 
se atingir a qualidade deve-se contar com recursos adequados, suficientes e efetivos, englobando infraestrutura e pessoal, além de uma gestão acadêmica e administrativa eficaz (DIAS SOBRINHO, 2011). Já a OCDE entende que a qualidade é aferida por seus resultados e em sua comparação permanente, instituindo para tanto os exames internacionais para diversos níveis educacionais (TEODORO, 2011). A Unesco e a OCDE, em conjunto, têm promovido algumas ações no intuito de promover a qualidade do ensino superior e, em 2006, lançaram o documento "Directrices en materia de calidad de la educación superior a través de las fronteras", que tem entre seus objetivos assegurar a transparência dos processos de avaliação dos cursos de graduação a fim de aumentar sua credibilidade internacional e apoiar a cooperação internacional entre as agências nacionais responsáveis por esses procedimentos (SIUFI, 2009). Dias Sobrinho (2011) chama atenção para o fato de que a OCDE não apenas define instrumentos, indicadores, metodologias e objetivos da avaliação e acreditação, como também forma expertos nesta área e recomenda boas práticas.

Dias Sobrinho (2011) observa que a qualidade torna-se mais perceptível por meio de elementos que permitem estabelecer uma comparação entre as expectativas (reais ou utópicas) com os resultados obtidos, enveredando por este caminho as definições mais correntes de qualidade, consistindo basicamente na adequada correlação entre tais expectativas e o que a IES, o curso ou o programa consegue demonstrar. Para esse autor, se por um lado é mais fácil reconhecer a qualidade por meio de critérios performáticos objetivos, por outro, defini-la e a forma como avaliá-la constitui-se em uma tarefa complexa, considerando que consiste em uma construção social.

Embora a avaliação da qualidade seja o cerne dos processos de internacionalização da educação superior, lembra Villanueva (2011) que a busca pela qualidade não é própria desses movimentos, mas é inerente à essência da universidade, diferenciando-se neste momento pelas instâncias educativas envolvidas; se inicialmente eram priorizados valores de mérito, tradição e prestígio para um número reduzido de indivíduos nas fronteiras do Estado-nação, o desafio da atualidade está em se oferecer um ensino superior de massa eficiente e de eficácia que atenda simultaneamente aos padrões internos e às exigências para sua transnacionalização, impondo a verificação quantitativa do mérito. Esta capacidade dos atores sociais de agir localmente pensando globalmente tem sido denominada de glocalização (VILLANUEVA, 2011).

Segundo Verhine e Freitas (2012), a educação é levada, a partir da década de 1980, a elevar os padrões de qualidade aos níveis internacionais de competitividade, passando a avaliação a ter importância progressiva no controle e eficiência da produtividade das IES, especialmente para obtenção de dados que possam ser utilizados como parâmetro de comparação com outros sistemas de educação superior.

Outra modificação apontada nessa transição por Rasetti (2009) refere-se ao próprio processo de avaliação, recordando que, anteriormente, as avaliações recorrentes no ambiente universitário estavam voltadas às pessoas e que a instrumentalização das práticas avaliativas tem assumido o fim de impelir a entrada de IES no mercado na medida em que a certificação de sua qualidade ocasiona prestígio da instituição no meio social e o aumento de seu grau de atratividade, orientando na escolha de um curso pelos mais variados motivos.

Tunnermann (2009) alerta para o fato de que o sistema universitário é intrinsecamente complexo e resulta de vários fatores e processos, não se limitando aos eixos básicos de ensino, pesquisa e extensão ou às análises estruturais ou curriculares, transcendendo a própria concepção que se tem do indivíduo, da sociedade e do conhecimento, não podendo ser abarcado em sua inteireza por definições de qualidade e de critérios para avaliá-lo. 
Recordando que a educação superior como objeto de estudo sistemático é relativamente recente e está vinculada à transformação da universidade de elite para a universidade de massa, Neave (2001) atribui a complexidade do sistema universitário a sua diversidade de formas, tarefas institucionais e variedades de constituição, entre outros fatores, o que dificultaria sua apreensão como objeto de avaliação.

A tarefa de identificar os elementos de pertinência e qualidade da educação superior, dada sua complexidade, foi assumida pelos agentes gestores e de influência na determinação burocrático-legal e ideológica hegemônicos do setor para viabilizar os processos de avaliação da qualidade de instituições, cursos, diplomas etc. (DIAS SOBRINHO, 2011). Nota Dias Sobrinho (2011) que, se de outra forma fosse, em face da diversidade de entendimentos da comunidade acadêmica sobre o tema, não seria possível se proceder a aferições de cunho avaliativo, justificando-se nesse caso a ação de tais atores por exercerem funções próprias da responsabilidade pública de controle estatal sobre a educação superior. Complementa esse autor que a solução adotada mundialmente foi conferir às agências reconhecidas pelos Estados ou organismos multilaterais a competência para conceber definições, parâmetros e metodologia acerca da qualidade, o que corresponde a elaborar modelos e a eleger os instrumentos adequados e igualmente defini-los. Assim, tais instrumentos assumem determinada feição dependendo das concepções e dos usos que lhes são atribuídos pelo sistema de avaliação do qual fazem parte, devendo ser aplicados de acordo com as diretrizes estipuladas.

Conforme Verhine e Freitas (2012), surgem dois modelos de avaliação da educação superior: um de caráter externo às IES, no qual é enfatizada a regulação, o controle e a hierarquização visando averiguar a eficiência e produtividade e o estabelecimento de rankings como forma de compará-las; e outro de caráter interno, que busca valorizar as questões intrínsecas ao ambiente universitário e a solução de seus problemas, contando para tanto, na maioria das vezes, com processos de autoavaliação esteados em princípios de participação e de gestão democrática das IES, orientados para as transformações qualitativas e para seu papel como produtoras de cultura e de conhecimento. Para esses autores, se o objetivo da avaliação for a melhoria das IES, a autoavaliação se mostra imprescindível como oportunidade para que possam se autocriticar e averiguar seus pontos fortes e fracos. Para Fitzpatrick, Sanders e Worthen (2004), a combinação das avaliações interna e externa proporciona olhares diferenciados sobre o mesmo objeto, podendo-se usufruir das vantagens de ambos os tipos de abordagem; se por um lado o avaliador interno conhece bem o curso, por outro, está tão envolvido no processo que se torna difícil identificar suas deficiências, o que pode ser feito de forma mais objetiva pelo avaliador externo.

Assim, tem-se que a determinação do modelo de avaliação também depende de como é compreendida e definida. Ao analisar algumas definições de avaliação, Ristoff (2003) aponta que ela pode ser entendida de diversas maneiras: 1) como processo em que se visa determinar o alcance de objetivos pré-estabelecidos (Tyler); 2) como forma de coleta de informações voltada para tomada de decisões (Cronbach); 3) como descoberta da natureza e do valor de determinado objeto (Stake); 4) como investigação sistemática do valor e do mérito de um objeto (Joint Commitee on Standards for Evaluation); 5) como estudo destinado a auxiliar o público a julgar e a aperfeiçoar o valor de determinado objeto educacional (Stufflebeam); 6) como processo de determinação do mérito, valor de mercado e o valor das coisas (Scriven) e, ainda, posicionamentos no sentido de que a avaliação não deve ser definida, pois definições limitam a compreensão do objeto em si (Guba e Lincoln).

Acerca dos conceitos de avaliação, de uma forma geral, considera Dias Sobrinho (2011) que, embora busquem a universalidade, não há como considerá-los neutros se se atentar para o 
lugar social dos sujeitos que determinam quais são os valores e objetivos almejados; ademais, padrões e critérios abstratos e genéricos não levam em conta as especificidades das áreas de conhecimento e da realidade local e implicam a imposição de um único modelo, como se a educação superior devesse ser estandardizada.

Fitzpatrick, Sanders e Worthen (2004) entendem que o estabelecimento da metodologia do processo de avaliação compreende algumas etapas que caracterizariam a avaliação formal, entendida esta como sistematizada e pública, tais como definir os padrões para julgar a qualidade e concluir se devem ser relativos ou absolutos, a forma de coleta de informações relevantes e como serão aplicados os padrões para determinar valor, qualidade, utilidade, eficácia e importância do objeto avaliado. Apontam esses autores noções elementares menos controversas sobre qual seja o papel da avaliação para se determinar os objetivos dos sistemas avaliativos, como os tipos formativo e somativo de avaliação, cunhados por Scriven. Sinteticamente, a avaliação formativa (improvement oriented) objetiva proporcionar a melhoria do objeto avaliado, voltada especialmente aos gestores da IES, cursos, programas etc., enquanto a somativa (accountability oriented) tem fins de auxiliar os responsáveis pela tomada de decisões sobre o objeto avaliado e a seus beneficiários ou potenciais beneficiários fornecendo-lhes julgamentos de valor ou mérito em relação a critérios considerados relevantes, consistindo na verificação de cumprimento de requisitos tidos como desejáveis. Ainda observam esses autores que os usos dessas avaliações variam de acordo com o público ao qual se direcionam, podendo ser composto desde órgãos de fomento a estudantes que pretendem ingressar no ensino superior. Desta feita, de acordo com os usos e concepções do plano em que se insere, a avaliação pode assumir o formato de instrumento externo de controle/ regulação ou ser apropriada desde o prisma formativo/emancipatório, podendo incluir procedimentos internos e externos.
Dias Sobrinho (2005) agrega outras características aos modelos de avaliação apresentados por Verhine e Freitas (2012), denominando-os como avaliações estáticas/tecnicistas e avalições dinâmicas/participativas. As primeiras seriam externas e aplicadas por equipes técnico-burocráticas, objetivando a obtenção de resultados, produtos e rendimentos entre os objetos avaliados, caracterizando-se na maioria das vezes como somativas e objetivas; desta feita, este tipo de avaliação pressupõe que a qualidade pode ser medida e deve ser classificada, sendo geralmente utilizada para o estabelecimento de rankings com o intuito de orientar a sociedade e notadamente os usuários de serviços educacionais. As avaliações dinâmicas e participativas fundam-se em um sentido ético-político, avaliando os produtos e resultados de outra perspectiva, relacionando-os com as causalidades, condições de produção, processos e contextos, apresentando-se prevalentemente como formativas, ainda que possam utilizar técnicas somativas. 0 grande diferencial desse tipo de avaliação está em possibilitar uma reflexão sobre a responsabilidade do objeto avaliado como elemento do sistema educacional na sociedade, tendo como função a produção de sentidos para direcioná-lo ao melhoramento.

O desenvolvimento dos paradigmas, para a avaliação da educação superior, auxiliou na construção de outro instrumento, a acreditação, dado o entendimento de que não seria suficiente apenas averiguar os níveis de qualidade, mas de comprová-los, como abordado na sequência.

\section{Acreditação e Certificação de Qualidade}

Além da avaliação como forma de verificação a priori da qualidade, passa a ser recomendada por organismos internacionais, como o Banco Mundial, a prática da acreditação, adotada nos Estados Unidos desde o final do século XIX, caracterizada pela avaliação externa feita por pares como forma de garantir a legitimidade 
do processo avaliativo, contando, para tanto, com a aceitação dos representantes/gestores do objeto de avaliação (VERHINE; FREITAS, 2012). Para Stubrin (2005), corroboraram para a adoção da avaliação e a acreditação como estratégias para ordenar o setor educacional os problemas de controle e qualidade ocasionados pela expansão desordenada, e potencialmente caótica, do número de instituições, programas, professores e alunos.

0 ponto-chave do processo de acreditação reside em se outorgar ao final de processo avaliativo, cujo resultado tenha sido considerado satisfatório, declaração de qualidade dotada de fé pública ao objeto avaliado. Almeida Júnior e Catani (2009) compreendem a acreditação como processo no qual se reconhece a qualidade de uma instituição, curso ou programa pertencente a determinado sistema educativo.

A despeito da relação entre avaliação e acreditação, advertem Márquez e Marquina (1998, p. 13) que "La evaluación de la calidad y la acreditación guardan estrecha relación, pese a ser procesos diferentes. La acreditación exige como proceso previo la evaluación aunque todo proceso evaluativo no tenga necesariamente como objetivo la acreditación". Desta forma, cabe diferenciá-las em razão de seus objetivos, embora possam se referir ao mesmo objeto, no caso, determinado item do ensino superior, entendendo-se a avaliação como pressuposto da acreditação, já que enquanto uma tem em vista a averiguação, a outra consiste em declaração de qualidade a partir de resultado obtido em processo avaliativo. Assim, a acreditação prescinde da avaliação, mas a avaliação nem sempre tem fins acreditatórios. Nota Dias Sobrinho (2011) que a acreditação vem substituindo a avaliação, reduzindo-se esta a um instrumento para se chegar àquela.

Ante a observância da conformação da acreditação como decorrência positiva de um processo avaliativo de averiguação de qualidade, emanam questionamentos acerca da própria essência desses processos avaliativos e no que consistiria o reconhecimento de qualidade.
Ajuíza Rasetti (2009) que os significados de avaliação e acreditação variam na literatura específica e estão intrinsecamente atrelados às políticas públicas da qual fazem parte. Assim, tem-se que a acreditação está intimamente ligada à questão da garantia da qualidade e, em decorrência disso, também há certa dificuldade em se definir acreditação, como ocorre com os demais termos. Diante das ambivalências que podem assumir os conceitos de processos de avaliação e acreditação no meio acadêmico, Dias Sobrinho (2008) reconhece como fonte desses discursos difusos a complexidade desses fenômenos e de seus desdobramentos nos planos teórico, prático e político-filosófico, podendo ser acrescido o fator jurídico, reforçando seu entendimento de que a melhor solução seria deixar a cargo dos órgãos de Estado competentes a definição dos conceitos operacionais de todo o sistema de avaliação, incluindo a acreditação.

De qualquer forma, o ato de acreditar cabe, por fim, ao Estado, seja via administração direita ou indireta ou por órgãos por ele autorizados como decorrência do seu poder de polícia. ${ }^{2}$ Acreditar, em si, implica garantir a qualidade perante a sociedade, de outorgar fé pública para o exercício da titularidade dos direitos dela decorrentes, observando-se que sua natureza jurídica é declaratória, consistindo no reconhecimento de uma situação pré-existente. Neste viés, pontua Dias Sobrinho (2008) que o foco principal da acreditação é o controle legal-burocrático da garantia da fé pública de qualidade, enquanto Almeida Junior e Catani (2009) reconhecem o instituto como uma espécie de certificação.

O caráter de certificação de qualidade da acreditação tem ensejado a aplicação de padrões internacionais de gestão de qualidade para o setor educacional, como as normas ISO $^{3} 9000$ (fundamentos e vocabulário) e ISO

2 Segundo Odete Medauar (1999), o poder de polícia referese à prerrogativa da Administração pública de impor limites ao exercício de direitos e liberdades em prol do interesse público.

3 A denominação "ISO" refere-se ao radical grego utilizado 
10015 (diretrizes para treinamento), notando Viebrantz e Morosini (2009) que são normas genéricas e que sua aplicação à área da educação superior é dificultada pela natureza que lhe é peculiar. Essas autoras entendem mais adequada a consulta à ISO/IEC 197961, publicada em outubro de 2005, que visa à convergência de abordagens de qualidade que são utilizadas especificamente na área da aprendizagem, educação e formação, não se tratando propriamente de uma norma, mas de uma ferramenta que estabelece uma linguagem comum de qualidade para auxiliar gestores e usuários a elaborar seus próprios sistemas, contribuindo para a integração de qualidade das organizações educacionais.

Verhine e Freitas (2012) notam que a acreditação tem por escopo o cumprimento de requisitos mínimos que conduzem ao reconhecimento oficial das IES, cursos ou programas, entendendo-se que foram atendidos os padrões básicos de qualidade aceitos, seja para fins regulatórios ou simbólicos. Já Dias Sobrinho (2011) entende que a finalidade da acreditação da educação superior é o acompanhamento da qualidade acadêmica continuamente.

Dias Sobrinho (2011), ao analisar o processo de acreditação, propõe sua esquematização. A primeira consideração pressupõe que o processo de acreditação está fundamentado em procedimentos avaliativos de duas ordens, interna e externa. A avaliação interna, geralmente, é realizada utilizando-se a autoavaliação, protagonizada pelo objeto avaliado, consistindo na emissão de um informe no qual se fundamentará a avaliação externa, coordenada e supervisionada por agências autorizadas para tanto ou por órgãos da administração central e feita por pares avaliadores, integrantes da comunidade científica, acadêmica ou profissional a partir de visita in loco.

para expressar igualdade. As normas ISO são emitidas pela International Organization for Standardization (IOS), organização não-governamental criada em 1947 e sediada em Genebra, que visa promover a normatização de produtos e serviços estabelecendo indicadores de qualidade (INTERNATIONAL ORGANIZATION FOR STANDARDIZATION, 2013).
Para fins de acreditação, na elaboração do informe de autoavaliação, devem ser seguidos os critérios e procedimentos previstos pelo órgão/agência de acreditação responsável pelo processo, versando, em regra, sobre seu histórico, recursos humanos, materiais e resultados.

A avaliação externa é realizada, comumente, por pares acadêmicos indicados pela agência de acreditação ou equivalente, que seleciona previamente os pares cadastrados a partir de critérios, sendo os mais usuais a titulação, o conhecimento dos conteúdos curriculares, a capacidade para reconhecer competências e habilidades de sua área e a experiência em outras instituições nacionais ou internacionais, entre outras. A tarefa dos pares consiste em elaborar uma análise em forma de texto esteada no informe de autoavaliação, nos documentos institucionais e nas percepções quanto ao cumprimento dos indicadores na oportunidade da visita, podendo contribuir com sugestões que entenderem pertinentes.

Com base na conjugação das informações colhidas nos procedimentos interno e externo, o órgão responsável pelo processo de acreditação emite um ditame, tido como avaliação final e de caráter técnico, outorgando ou não a acreditação do objeto em avaliação, que posteriormente é remetido para as autoridades governamentais para ciência e para que surta os devidos efeitos previstos na legislação. Sobre o ditame final, Dias Sobrinho (2011) esclarece que, além dos juízos binários (sim-não) sobre o cumprimento dos critérios de verificação de qualidade, podem vir acompanhados de recomendações que visam à melhoria ou mesmo de protocolos de compromisso objetivando solucionar os problemas encontrados em um lapso temporal determinado. 0 grau de qualidade do objeto avaliado é proporcional ao seu ajuste aos padrões estabelecidos; deste modo, a excelência passa a ser atrelada à correspondência aos indicadores externos previamente determinados por um órgão ou agência e não à pertinência e demandas sociais. 
Deve-se atentar para o fato de que o processo de acreditação não deve ser confundido com os procedimentos avaliativos ex ante para a autorização de funcionamento, que tem como objeto a infraestrutura praticamente, apresentando-se como mais complexo, tanto do ponto de vista metodológico como conceitual (DIAS SOBRINHO, 2011).

Quanto aos órgãos que executam os processos de acreditação, nota Dias Sobrinho (2011) que podem ser nacionais, regionais ou internacionais, públicos ou privados, e, ainda, que dependendo do país, a acreditação pode ser obrigatória ou voluntária e, na maioria das vezes, limitada temporalmente.

Nos processos de acreditação, a figura das Agências Nacionais de Acreditação (ANAs) exerce a função central na determinação das diretrizes e padrões aplicados, na coordenação dos procedimentos de avaliação interno e externo, de prolatar a decisão final e de outorgar formalmente a acreditação. 0 protagonismo das ANAs no processo de acreditação pode ser interpretado como redução da autonomia universitária, dependendo da forma como se desenvolve a implementação do processo e da relação que se estabelece com a comunidade acadêmica.

Com base nos elementos discorridos, poderse-ia apresentar uma classificação da acreditação para fins de visualização das múltiplas esferas e formas que se aplica, adotando-se como critérios a espacialidade, o objeto, a obrigatoriedade, a finalidade e a eficácia.

No tocante à validade espacial, seriam focadas as limitações territoriais em que a acreditação produz efeitos, assim, podendo ser: 1) nacional, se válida apenas no território do Estado que a outorgou; 2) bilateral, se sua validade é estendida ao território de outro Estado via acordo; 3) multilateral, se sua validade é reconhecida via acordo em mais de um Estado além do que a outorgou; 4) regional, se está inserida no contexto de um bloco econômico ou agregação geográfica de Estados que apresentam contiguidade territorial.
Quanto ao objeto, ter-se-ia em vista o elemento do sistema educacional que se submete ao processo de acreditação, podendo ser: 1) de instituições; 2) de programas; 3) de curso. Esta classificação é uma das mais usuais.

Já em relação à obrigatoriedade, levar-se-ia em consideração sua relação com a Administração Pública, podendo figurar como: 1) voluntária; 2) obrigatória; 3) mista, sendo obrigatória para alguns cursos.

Na classificação pela finalidade, seria analisada a motivação geradora do processo, tendo-se: 1) para controle/regulação, com processos avaliativos de cunho somativo; 2) para melhoria do objeto avaliado, com processos avaliativos de caráter formativo; 3) mista, prestando-se à conjugação das duas finalidades anteriores.

Por fim, a acreditação poderia ser classificada quanto a sua eficácia, isto é, aos efeitos que produz, podendo ser: 1) formal ou simbólica, se não produz nenhum efeito, além do prestígio advindo do reconhecimento de qualidade; 2) material, se produz efeitos concretos agregados ao simbólico, constituindo-se como requisito para o reconhecimento de títulos, atos autorizativos, programas de mobilidade etc.

A acreditação demonstra sua faceta instrumental nos processos de internacionalização, transnacionalização e regionalização da educação superior ao possibilitar a convergência de critérios de aferição de qualidade nesses níveis e viabilizar o reconhecimento de títulos acadêmicos expedidos alhures, possibilitando a mobilidade tanto acadêmica quanto profissional. Embora a acreditação tenha sido trazida à ribalta como recomendação de organismos internacionais pela motivação de aumentar o fluxo do comércio de bens e serviços, pode também se apresentar como forma de resistência contra-hegemônica a esses processos, dependendo dos padrões de qualidade adotados e se se partir do entendimento de que a educação superior se constitui em um bem público ou parte dos direitos humanos, devendo ser assegurada e ofertada pelo Estado. 
Verhine e Freitas (2012) chamam atenção para a elevação da educação superior ao nível de um bem mundial de interesse global, participando desse movimento de internacionalização interlocutores públicos e privados, além da representação oficial dos Estados. Para Rama (2009), este entendimento desloca a educação superior da esfera interna para a internacional, ensejando a responsabilização da comunidade internacional no sentido de contribuir e velar para que possa ser acessada por todos.

Teodoro (2011) ressalta que os processos de globalização alteraram radicalmente as prioridades da agenda da educação superior; se antes era pautada pelos ideais sociais-democratas de igualdade de oportunidades e qualidade no Estado de bem-estar social, no Estado-avaliador/regulador passou a buscar uma qualidade vagamente definida com base na trilogia competitividade, accountability e desempenho. Assim, a acreditação entra na pauta do dia da educação superior como ferramenta para a viabilização da circulação de pessoas altamente qualificadas ou em qualificação, tanto na área profissional como acadêmica, não se podendo tratar da internacionalização da educação superior sem se entrar no mérito da certificação de qualidade do título portado. Mesmo os movimentos que concebem a educação superior como direito ou bem público prescindem de mecanismos de comparabilidade para a mobilidade estudantil, para o intercâmbio de professores e pesquisadores e para o reconhecimento de títulos. A seguir, passa-se à explanação de alguns modelos de avaliação e acreditação da educação superior.

\section{Modelos de Avaliação e de Acreditação da Educação Superior}

A ascensão da avaliação e da acreditação como instrumentos de averiguação e certificação da qualidade nos processos de internacionalização da educação superior, a partir dos anos 1980, não implica em seu uso uniforme, tendo-se em vista as diversas compreensões sobre a funcionalidade desses processos, das diferentes formas de globalização, do grau de integração dos blocos econômicos regionais e, notadamente, do posicionamento dos Estados em face de sua prerrogativa soberana de determinar os limites para a atuação de entes estrangeiros e de aplicação de recomendações de organismos internacionais em seu território.

Rama (2009) aponta a discrepância entre alguns desses cenários, observando que, enquanto na América Latina o foco é a passagem da educação público-privada para a tripartida, com a inserção dos provedores estrangeiros, sem políticas regionais de acreditação fortalecidas, na Europa a educação superior passa a ser regulada regionalmente, a partir da adesão dos Estados à Declaração de Bolonha de 1999, sendo marcado esse processo pela desnacionalização, formulação de políticas públicas conjuntas e convergência dos sistemas nacionais de educação superior. Para esse autor, esses diferentes quadros possibilitam a difusão de novas modalidades de cooperação entre os Estados e as universidades, requerendo reflexão sobre a facilitação da drenagem de capital humano no marco da divisão internacional de trabalho na sociedade de conhecimento.

Para Siufi (2009), nessa nova geopolítica mundial, a cooperação internacional universitária, com base em ações horizontais, também tem experimentado outras modalidades como consequência dos processos relacionados ao fortalecimento da qualidade e pertinência das instituições, tendendo a ser compreendida como meio para o desenvolvimento institucional e como modo de complementação das capacidades das universidades, permitindo a realização de atividades conjuntas e uma integração com fins de benefícios recíprocos, apresentando-se, então, como uma via contra -hegemônica. Neste modelo, estruturado em redes e espaços comunitários de cooperação e colaboração, busca-se preservar as identidades universitárias locais, adotando-se como refe- 
rencial as principais recomendações emanadas das Conferências Mundiais sobre Educação Superior da Unesco, incluindo os processos de acreditação (RAMA, 2009).

No que diz respeito a esse tipo de cooperação na América Latina, Guadilla (2004) assegura que é a mais antiga e importante forma de relação entre as IES, e os convênios continuam sendo o mecanismo insuperável para a celebração de relações externas. Ademais, segundo essa autora, tendo em conta que os países que não logrem estabelecer um sistema de garantia de qualidade da educação superior estejam relegados a permanecer na periferia da economia global, os convênios se postam como meio de construir uma qualidade que leve em consideração a pertinência em relação à sociedade local. Para Guadilla (2004), os sistemas internacionais de acreditação deveriam tomar como referência critérios de cooperação que respeitem a diversidade cultural e as tradições dos Estados, conciliando-os com as aspirações dos setores público e privado, e dos provedores transnacionais.

Nos panoramas regionais específicos, destaca Dias Sobrinho (2011) que os blocos econômicos têm-se mostrado espaços prolíficos para ações coordenadas diretas e indiretas relativas a práticas de acreditação ante seu peso político e econômico no fomento da circulação de pessoas, mencionando o North American Free Trade Agreement (Nafta) ${ }^{4}$ e o Mercado Comum do Sul (Mercosul), além da União Europeia. Desses três processos, o Nafta imprimiu menor impacto no tocante à questão da acreditação de títulos no bloco, tendo em vista que a certificação de qualidade é uma prática amplamente adotada e consolidada nos Estados Unidos e no Canadá, requerendo do México esforços para se alinhar (VERHINE; FREITAS, 2012). Segundo Damme (2002), em razão da mobilidade profissional prevista no Acordo, as agências de acreditação estadunidenses trabalharam

4 O Nafta é um acordo que estabelece uma área de livre comércio entre Canadá, Estados Unidos e México o qual entrou em vigor em $1^{\circ}$ o de janeiro de 1994 (UNITED STATES TRADE REPRESENTATIVE, 2013). em cooperação com o México para a criação de agências de acreditação nos seus moldes. Diversamente, no Mercosul e na Europa foram estabelecidos procedimentos coordenados nacionalmente com normas estabelecidas por uma rede de agências nacionais de acreditação (Rana) e por uma associação externa (European Association for Quality Assurance in Higher Education - ENQA), com o escopo de se constituir um espaço regional de educação superior.

Como parte da integração regional, Guadilla (2004) menciona ainda os acordos inter-regionais para a criação de espaços de interação como exemplo de internacionalização com cooperação, citando o Espaço Comum de Educação Superior União Europeia-América Latina por meio dos programas América Latina-Formação Acadêmica (Alfa) e o Programa de bolsas para latino-americanos na União Europeia (Alban). ${ }^{5}$

As redes de universidades e redes de acreditação destacam-se nesse quadro por articularem diversos países e regiões em prol da convergência da educação superior e prestarem auxílio a governos antes mesmo da intensificação da internacionalização do setor.

$\mathrm{Na}$ área da acreditação, algumas dessas redes têm-se destacado por promoverem o desenvolvimento de sistemas nacionais e regionais, como o Consejo Superior Universitario Centroamericano (CSUCA), o Centro Interuniversitário de Desarrollo (Cinda) e a Asociación Columbus.

O CSUCA, criado em 1948 e com sede na cidade da Guatemala, é organismo precursor da integração universitária e de redes na América Latina, contribuindo para o melhoramento da educação superior da América Central, funcionando dentro do marco do Sistema de Integração Centro-americano, sendo composto atualmente por 24 universidades (CONSEJO

5 0 Programa Alfa foi implementado entre 1994 e 2013 e contou com a contribuição de 163 milhões de euros da União Europeia, enquanto o Alban compreendeu os anos de 2002 a 2010 e orçamento de 84 milhões de euros. Atualmente, a cooperação entre Europa e América Latina no campo da educação superior se dá por meio do Programa Erasmus+ (2014-2020) (EUROPEAN COMISSION, 2019). 
SUPERIOR UNIVERSITARIO CENTROAMERICANO, 2019). Entre as maiores colaborações do CSUCA está a criação do Sistema Centroamericano de Evaluacíon y Acreditación de la Educación Superior (Sicevaes), que, juntamente com o sistema de acreditação do Mercosul, é o mecanismo sub-regional de asseguramento e acreditação da qualidade dos cursos de graduação mais importante da América Latina (LAMARRA, 2004).

Integrado por 37 universidades da América Latina e Europa e com sede na cidade de Santiago do Chile, o Cinda vem atuando desde a década de 1970 na área de consultoria e de assessoria para a melhora da gestão e da qualidade da educação superior, com diversas publicações sobre modelos de asseguramento da qualidade, priorizando-se temas como financiamento, regulação e informação (CENTRO INTERUNIVERSITÁRIO DE DESARROLLO, 2019).

Outra rede que envolve universidades latino-americanas e europeias é a Associação Columbus, criada em 1987 e com sede em Paris, que reúne 48 instituições como membros, 41 da América Latina e 7 da Europa, e suas ações são voltadas para a constituição de redes institucionais universitárias e capacitação de seus gestores, oferecendo serviços de avaliação, de auditoria e consultoria para universidades e governos (COLUMBUS, 2019).

Ao analisar as redes de universidades, Verhine e Freitas (2012) ponderam que elas têm contribuído muito para os avanços da acreditação, mas há riscos e desafios, pois, mesmo sendo consubstanciadas sob o princípio da cooperação solidária sem hegemonias, parte da comunidade universitária é partidária à transnacionalização mercantilista da educação superior, podendo eventualmente propagar entendimentos que se prestem a uma definição universal do que sejam boas e más práticas e defender ofertas comerciais que deveriam ser controladas e evitadas.

Entre as redes de acreditação, sobressai-se na América Latina a Red Iberoamericana para el Asseguramiento de la Calidad em la Educación Superior (Riaces), uma associação sem fins lucrativos criada em 2003 por agências de avaliação e acreditação da qualidade de diversos países da América Latina, pela Agencia Nacional de Evaluación de la Calidad y Acreditación (Aneca) da Espanha e por ministérios de educação da região. Atualmente, reúne 28 membros, em sua maioria agências de acreditação, e 5 organismos regionais, entre eles a Cinda, o Instituto Internacional para la Educación Superior en América Latina y el Caribe (Iesalc) e a Organização dos Estados Ibero-americanos (OEI), visando promover a cooperação e o intercâmbio sobre a matéria e contribuindo para a garantia da qualidade da educação superior entre seus membros (RED IBEROAMERICANA PARA EL ASSEGURAMIENTO DE LA CALIDAD EM LA EDUCACIÓN SUPERIOR, 2019). A Riaces é organizada por comissões de trabalho dedicadas a temas específicos: estudos comparados; gestão e manutenção de um site próprio; desenho de software para autoavaliação; oficinas de formação para avaliadores; glossário de termos de avaliação e de acreditação; boas práticas em avaliação; acreditação e estudo comparativo de títulos (LAMARRA, 2004).

Theiler (2005) destaca o trabalho da Riaces na elaboração de concepções conjuntas e coordenadas para os desafios colocados pelo processo de globalização em curso no ensino superior, figurando entre eles a própria definição de acreditação:

Processo para garantir a qualidade de uma instituição ou de um programa educativo. 0 processo é realizado por uma agência externa às instituições de educação superior. A acreditação - ou certificação - reconhece a qualidade de programas ou da instituição acreditada. (RED IBEROAMERICANA PARA EL ASSEGURAMIENTO DE LA CALIDAD EM LA EDUCACIÓN SUPERIOR, 2004 apud DIAS SOBRINHO, 2011, p. 21).

Desses modelos de rede de cooperação universitária e de redes de avaliação e acreditação pode-se apreender os esforços realizados em várias esferas e níveis para a difusão da cultura 
da garantia da qualidade do ensino superior, denotando sua importância amplificada promovida pela globalização e pelos processos de internacionalização da educação superior, não excluindo a intersecção dessas ações com as concentradas regionalmente, como na Europa e no Mercosul.

\section{Considerações Finais}

Ao longo do estudo denota-se que a projeção da acreditação como mecanismo de garantia da qualidade da educação superior resulta, notadamente, da flexibilização das fronteiras nacionais e da intensificação das diferentes demandas de circulação de acadêmicos, estudantes e profissionais diplomados observadas desde as últimas décadas do século XX.

Muito embora a acreditação não seja um instituto recente, esse cenário favoreceu sua adoção em larga escala, especialmente em face de seu revestimento legal, que a caracteriza como uma declaração de qualidade dotada de fé pública chancelada pelo Estado que, em última instância, a regulamenta.

Nesse diapasão, cabe salientar que a competência para implementar os processos de acreditação e executar os respectivos procedimentos avaliativos permanece sob a égide do Estado e se dá em âmbito nacional, não obstante possam haver políticas públicas intergovernamentais que acordem a harmonização de indicadores de qualidade e mesmo a convergência de sistemas educacionais nacionais.

Como discorrido no texto, o que se entende por educação superior em dada conjuntura determina não apenas o modelo de avaliação e de acreditação a serem adotados, como também está intrinsecamente ligado aos resultados esperados, ou seja, como se define qualidade, não havendo vazão para qualquer espécie de neutralidade. Desta feita, é nas diretrizes e nos acordos sobre o estabelecimento de processos de acreditação que se inscrevem os matizes da matéria e se descortinam a natureza da abordagem dispensada.
Independentemente do viés que oriente os processos de acreditação, o reconhecimento oficial de qualidade de IES, de programas e de cursos legitima a função social da educação superior enquanto instrumento de produção do conhecimento e de tecnologia. Esta garantia torna-se elementar para propiciar a circulação de mão de obra altamente qualificada, de acadêmicos e de estudantes, passando a acreditação a ser requisito de políticas públicas que se esteiam nos níveis educacionais mais elevados, assumindo o posto de principal tendência nos processos de internacionalização da educação superior.

\section{REFERÊNCIAS}

ALMEIDA JÚNIOR, V. de P.; CATANI, A. M. Algumas características das políticas de acreditação e avaliação da educação superior da Colômbia: interfaces com o Brasil. Revista da Avaliação da Educação Superior, Sorocaba, SP, v. 14, n. 3, nov. 2009.

CAILLÓN, A.; ROBLEDO, R. Procesos regionales en educación superior. El mecanismo de acreditación de carreras universitarias en el Mercosur. Reconocimiento regional de los títulos y de la calidad de la formación. Educación Superior y Sociedad, Caracas, ano 14, n. 1, p. 73-98, 2009.

CENTRO INTERUNIVERSITARIO DE DESARROLLO (CINDA). Sobre nosotros. Universidades miembros. Disponível em: https://cinda.cl/sobre-nosotros/universidades-miembros/. Acesso em: 3 maio 2019.

COLUMBUS. Universidades miembros. Disponível em: https://www.columbus-web.org/es/quienessomos/universidades-miembros.html. Acesso em: 3 maio 2019.

CONSEJO SUPERIOR UNIVERSITARIO CENTROAMERICANO (CSUCA). Miembros. Disponível em: http://www.csuca.org/index.php/business/universidades-miembros. Acesso em: 3 maio 2019.

DAMME, D. V. Trends and models in international quality assurance and accreditation in higher education in relation to trade in education services. Washington: OCDE, 2002.

DIAS SOBRINHO, J. Acreditação da educação superior. Seminário Internacional de Avaliação da Educação Superior. 2008. Disponível em: http://portal. mec.gov.br/index.php?option=com_content\&vie- 
$\mathrm{w}=$ article\&id $=15305$ : seminario-internacional-de -avaliacao-da=-educacao-superior2008-\&catid323: orgaos-vinculados\&Itemid=1075. Acesso em: 25 maio 2010.

DIAS SOBRINHO, J. Avaliação da educação superior, regulação e emancipação. In: DIAS SOBRINHO, J.; RISTOFF, D. (org.) Avaliação e compromisso público: a educação superior em debate. Florianópolis: Insular, 2003. p. 35-52.

DIAS SOBRINHO, J. Dilemas da Educação Superior no mundo globalizado. Sociedade do conhecimento ou economia do conhecimento? São Paulo: Casa do Psicólogo, 2005.

DIAS SOBRINHO, J. Qualidade e garantia de qualidade: acreditação da educação superior. In: ROTHEN, J. C.; BARREYRO, G. B. (org.) Avaliação da educação: diferentes abordagens críticas. São Paulo: Xamã, 2011. p. 17- 41.

EUROPEAN COMMISSION. International Cooperation and Development. Buiding partnerships for change in development countries. Latin America - Erasmus Mundus and Erasmus+: Partnership in higher education. Disponível em: https://ec.europa. eu/europeaid/regions/latin-america/erasmus -mundus_en. Acesso em: 3 maio 2019.

FITZPATRICK, J. L.; SANDERS, J. R.; WORTHEN, B. R. Avaliação de programas. São Paulo: Gente/ Edusp, 2004.

GUADILLA, C. G. Introducción: ¿Se desestabiliza la noción "bien público" de la Educación Superior? In: GUADILLA, C. G. et al (coord.). El difícil equilibrio: la educación superior entre bien público y comercio de servicios. Implicaciones del AGCS (GATS). París/ Cuenca/España: Edit. Columbus/Universidad de Castilla-La Mancha, 2004. p. 4-9.

INTERNATIONAL ORGANIZATION FOR STANDARDIZATION (IOS). About us. Disponível em: http:// www.iso.org/iso/home/about.htm. Acesso em: 13 mar. 2013.

LAMARRA, N. F. Hacia la convergencia de los sistemas de educación superior en América Latina. Revista Iberoamericana de Educación, Madrid, n. 35, p. 39-71, mayo-agosto 2004.

MÁRQUEZ, A. D.; MARQUINA, M. Evaluación, acreditación, reconocimiento de títulos y habilitación. Enfoque comparado. Buenos Aires: Coneau, 1998. (Série Informes).

MEDAUAR, O. Direito administrativo moderno. São Paulo: Revista dos Tribunais, 1999.
NEAVE, G. Educación superior: historia y política. Estudios comparativos sobre la universidad contemporánea. Barcelona: Gedisa, 2001.

RAMA, C. La tendencia a la internacionalización de la educación superior. In: LAMARRA, N. F. (org.) Universidad, sociedad e innovación. Una perspectiva internacional. Caseros: Universidad Nacional Tres de Febrero, 2009. p. 43-56.

RASETTI, C. P. Cuestiones teóricas y metodológicas de evaluación u acreditación. In: CURSO LATINOAMERICANO DE POLÍTICAS PUBLICAS Y EVALUACIÓN PARA LA EDUCACIÓN SUPERIOR, 2009, Foz de Iguazú. Anais [...]. Foz de Iguazú: Universidad Federal de la Integración latinoamericana (UNILA), 2009. Disponível em: http://ead.pti.org.br/unila/ course/view.php?id=7. Acesso em: 26 out. 2009.

RED IBEROAMERICANA PARA EL ASEGURAMIENTO DE LA CALIDAD EM LA EDUCACIÓN SUPERIOR (RIACES). Miembros. Disponível em: http://www. riaces.org/v1/index.php/institucional/miembros. Acesso em: 3 maio 2019.

RISTOFF, D. Algumas definições de avaliação. In: DIAS SOBRINHO, J.; RISTOFF, D. (org.) Avaliação e compromisso público: a educação superior em debate. Florianópolis: Insular, 2003. p. 21-33.

ROTHEN, J. C.; BARREYRO, G. B. Avaliação, agências e especialistas: padrões oficiais de qualidade da educação superior. Ensaio: Avaliação e Políticas Públicas em Educação, Rio de Janeiro, v. 17, n. 65, p. 729-752, out./dez. 2009.

SIUFI, G. Cooperación internacional e internacionalización de la educación superior. Educación Superior y Sociedad, Año 14, n. 1, p. 121-145, 2009.

STUBRIN, A. Los mecanismos nacionales de garantía pública de calidad en el marco de la internacionalización de la educación superior. Avaliação

- Revista da Rede de Avaliação Institucional da Educação Superior, v. 10, n. 4, p. 9-22, 2005.

TEODORO, A. A educação em tempos de globalização neoliberal. Os novos modos de regulação das políticas educacionais. Brasília, DF: Líber Livro, 2011.

THEILER, J. C. Internationalization of higher education in Argentina. In: DE WIT, H. et al (ed.). Higher Education in Latin America - the international dimension. Washington D.C.: The World Bank, 2005. p. 71-110.

TORRES, C. A. La educación superior en tiempos de la globalización neoliberal. In: LAMARRA, N. F. 
(org.). Universidad, sociedad e innovación. Una perspectiva internacional. Caseros: Universidad Nacional Tres de Febrero, 2009. p. 25-42.

TUNNERMANN, C. Pertinencia y calidad en la educación superior. In: LAMARRA, N. F. (org.). Universidad, sociedad e innovación. Una perspectiva internacional. Caseros: Universidad Nacional Tres de Febrero, 2009. p. 268-291.

UNITED STATES TRADE REPRESENTATIVE (USTR). North American free trade agreement. Disponível em: http://www.ustr.gov/trade-agreements/ free-trade-agreements/north-american-free-trade -agreement-nafta. Acesso em: 15 maio 2013.

VERHAINE, R. E.; FREITAS, A. A. da S. M. de. A avaliação da educação superior: modalidades e tendências no cenário internacional. Revista Ensino Superior Unicamp, Campinas, SP, v 3, n. 7, p. 16-39, 2012.

VIEBRANTZ, R.; MOROSINI, M. C. Qualidade e educação superior: a norma de qualidade para aprendizagem, educação e formação: ISO/IEC 19796-1. Educação, Porto Alegre, v. 32, n. 3, p. 277-285, set./ dez. 2009.

VILLANUEVA, E. F. Acreditación universitaria: confianza y legitimidad. Revista Iberoamericana de Educación, Madrid/Buenos Aires, n. 57, p. 53-70, set./dez. 2011.

Recebido em: 10/05/2019

Aprovado em: 05/07/2019 